ESSAYS

\title{
Multiple Motives: Selfishness, Altruism and Reciprocal Exchange in a Scottish Charity Shop
}

\author{
NATALIE NORTHRIDGE, PATRICK O’DOWD, \\ LEDA OLIA \& SAMANTHA REDFERN
}

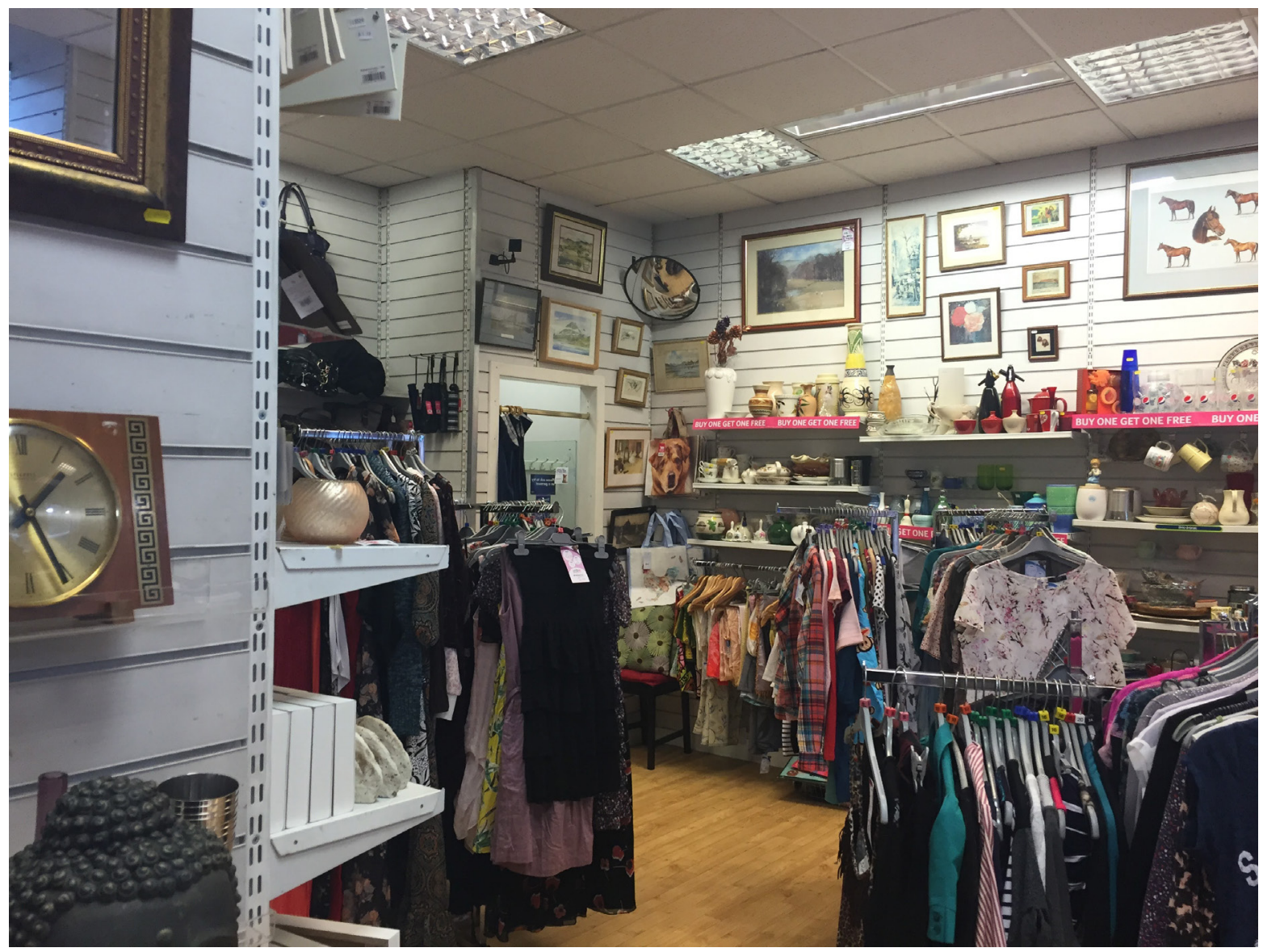

FIG I:The 'organised chaos' of the shop floor. (All photos (C Northridge et al.) 


\title{
Multiple Motives: Selfishness, Altruism and Reciprocal Exchange in a Scottish Charity Shop
}

\author{
NATALIE NORTHRIDGE, PATRICK O'DOWD, \\ LEDA OLIA \& SAMANTHA REDFERN
}

\section{Setting the scene}

"What's the most rewarding part of working in the charity shop?", we ask.

"You want me to say when I raise loads of money for the charity, don't you?" (Emma, Manager).

The UK's leading veterinary charity, PDSA (People's Dispensary for Sick Animals), provides care to ill and injured animals. The fieldwork we carried out in Edinburgh's PDSA branch caused us to question what we conceived as charity, and who the shop actually benefits.

Upon entering the PDSA charity shop on the corner of Nicholson Street and West Nicolson Street you are met with organised chaos. Muffled music from a small radio in the corner permeates the space, providing the shop with pop and casual conversation. Racks of newly labelled second-hand clothing are dotted around the room, arranged by colour and size. The walls are covered in horizontal panels, allowing shelves and hooks to be slotted in, creating a patchwork of wares. Nearly all of the white space is concealed behind bags, mirrors, clocks, DVDs, ceramics, books, and more, giving the shop a busy feeling. On the right-hand wall, bric-a-brac items balance precariously atop each other. The heater above blasts warm air and the Pepsi glasses, tightly displayed, gently jostle together; listening closely you can hear the sound of their clinking and chiming. The back wall is divided by a door leading into the stockroom.

Delving into the stockroom, the feeling is very different from the public facade. The room is not large, seeming smaller than it is due to the clutter filling it. The air feels heavy and the room dirty, with a thin layer of dust covering many of the items which are waiting to be sorted. Coloured bin bags containing 'rags' which will be recycled, are shoved into large metal cages. These also serve as hanging space for clothes deemed suitable for the shop floor straight away. Clothes deemed neither 'rags' nor ready for sale are hung on the bars around the walls. It seems impossible that more could be stored due to the density of the rails but pushing the clothes forcefully will create precious space. Wooden shelves on the right-hand side wall are masked by stacks of plastic tubs and shoe boxes holding extra stock. This room is adjoined by a small, dank kitchen and the manager's office

\section{Methodology}

We were eagerly welcomed into the shop by the manager, who saw our research project as an opportunity to gain a few extra hands on the shop floor. This space soon became our home for two hours each Thursday afternoon, or more if we could spare it. We volunteered within the shop for seven weeks, conducting our research through participant observation, casual conversation and semi-structured interviews. We took detailed, reflexive field notes, both physically and mentally. Despite being there to do research we were treated the same as any other volunteer. This active immersion into the environment allowed us to witness a normal day in the shop and gain insight into the inner workings of this space. Although our time there did involve work, much of the observation was relaxed. We would chat with volunteers whilst moving around the shop, being careful to make the purpose of our project clear and acquire informed consent (Crow et al 2006: 83). We built rapport with the other volunteers, which led to open conversations and topical discussion. Additionally, we carried out formal audio-recorded semi-structured interviews about halfway through our research period with three volunteers and the manager. These interviews allowed us to delve more deeply into motivations and contradictions we had observed. 
The mental health of some volunteers was called into question. We were unsure of the ethics surrounding their inclusion in the project, however, we decided that to exclude these people would be neither helpful nor fair. They are in this space as any other volunteer, so we treated them as such. That being said, we did not interview these people in particular as we thought they might feel put on the spot.

Furthermore, we encountered some issues which may have affected the outcome of our fieldwork and conclusions. As we visited the shop at the same time each week, and the people we encountered as volunteers only work certain days, perhaps we would have told a different story if we had gone at different times. Edinburgh is also a very student-heavy city, which could have altered the demographic of volunteers we worked with. In our experience, the volunteers were mostly under 30, opposing the conclusions drawn by Horne and Broadbridge (1994: 209-211) who surveyed Scottish volunteers, finding that only 1\% were students and most were aged between 55 and 74 years old.. At times the charity shop became very busy with both volunteers and customers and it is possible our being there, as a group of four, might have changed the dynamics. Lastly, we went into the fieldwork with the intention of speaking to volunteers, donors and customers but in practice we found the public less willing to speak than we expected. This has led to our ethnography being volunteer-focused andfurther research is perhaps needed to delve into the motivations of these two other aspects.

\section{What is charity?}

The word 'charity' comes from the Latin wordcaritas, meaning to care for (Malik, 2008: 1). The colloquial form of charity usually refers to philanthropy: the act of 'selfless giving' from the wealthy to those less fortunate. Portrayed as a selfless actcharity work is the epitome of Mauss' 'pure gift' (Mauss, 1954: 93).

Throughout our fieldwork questions began to arise over this perception of charity as pure altruism, causing us to reconsider our preconceptions of the meaning of charity. Rather than being a selfless act, we came to understand it as a mutually beneficial transaction. In terms of the charity shop the reciprocal exchange is perhaps most clearly exemplified with the purchase of goods. Regardless of whether the customer was shopping at the charity shop for noble reasons, they get their item cheaply and the money earned goes towards a 'cause'.

Volunteering at a charity shop can also be regarded as an exchange, though this is perhaps not as immediately obvious as there is no apparent material gain involved. However, whether it is an incentive to get out of the house or gain work experience, we found that volunteer work at a charity shop was done primarily for personal reasons, rather than altruistic ones. Interestingly, a study done by Parsons and Broadbridge showed if a manager leaves to work for another charity, the volunteers often leave too to join them (2006: 128). Therefore, it is not a loyalty to a certain charity that encourages people to give up their time. The volunteers are not exclusively there for philanthropic reasons, but for some sort of personal gain or fulfilment. Thus, similar to the other aspects of charitable giving, charity work is best understood as an exchange.

\section{Charity as a selfish act}

Our initial perception of the PDSA shop was one of warmth and generosity. Emma, one of two managers in the shop, created much of this atmosphere through her confidence and reputation as a friendly troublemaker. Her enthusiasm and pride was contagious and the volunteers mirrored her commitment to helping "pets in need of vets", just as the PDSA's slogan on the side of the shop instructs. This was our perception until we conducted our interviews at the small, square table in the pokey kitchen at the back of the charity shop, dimly lit by an old, bare light bulb. It is in this private space, where volunteers are not bound to the till, or obligated to organise the overflowing clothing racks, where stories are exchanged.

While conversing with Emma, it became clear we had misunderstood many of the motives attracting staff to the shop. On asking her about the most rewarding aspect of managing the shop, she laughed. "You want me to say when I raise loads of money for the charity, don't you?" She paused briefly and continued, "I like making money because I like being one of the biggest and most profitable shops we've got. I wouldn't say it's particularly because I'm like 'ooh PDSA'." Emma's motives seemed to be grounded in personal pride 

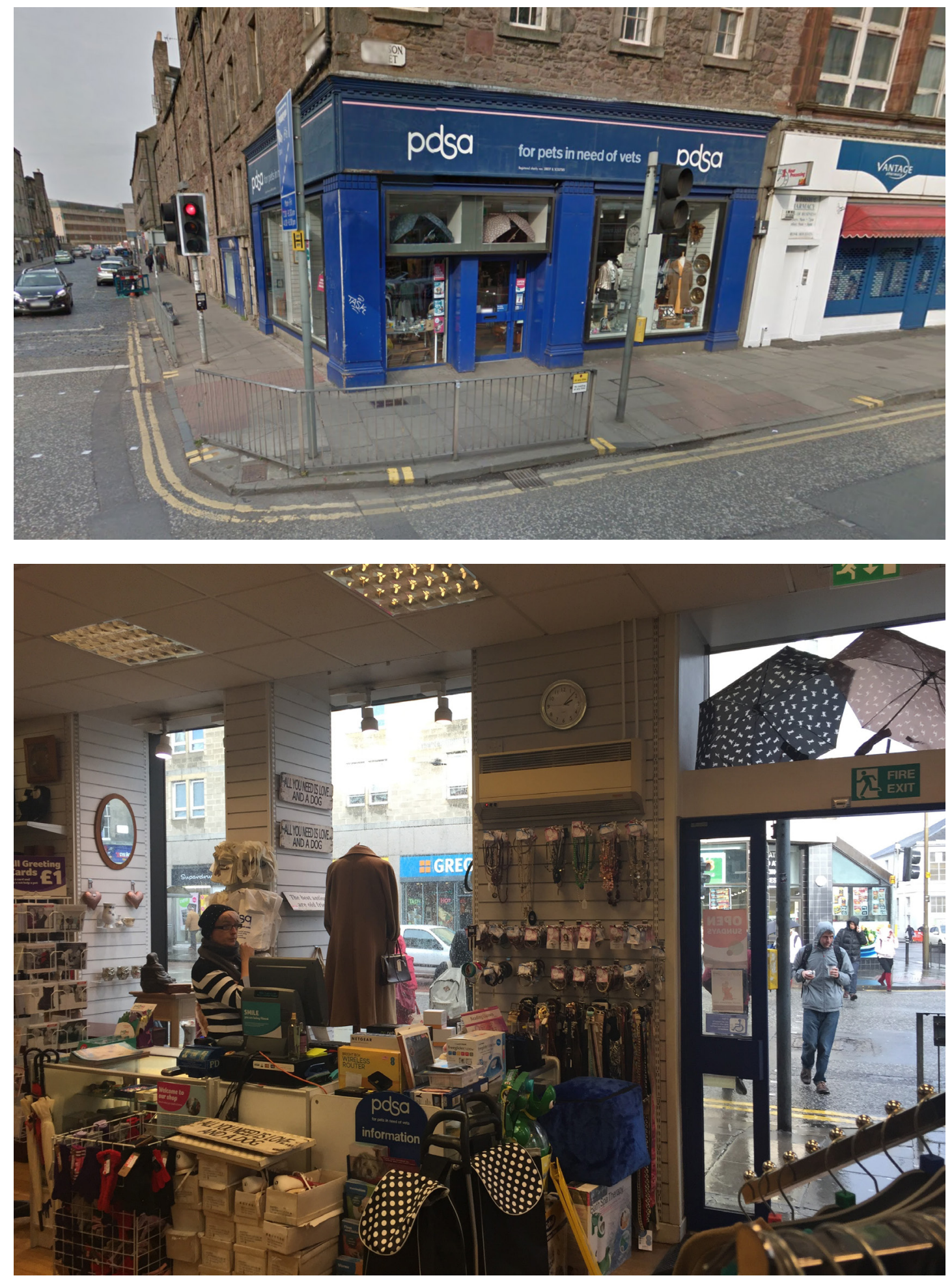

FIG 2: Entrance to the shop from Google Street View 2016 (top); FIG 3: Shop entrance facing Nicholson Street (bottom). 
and a desire to prove her managerial skills. Her PDSA shop is the third most profitable shop in Scotland and maintaining this is important to her.

This was a turning point in our experience. It became clear that very few, if any, of the volunteers we came across had a personal interest in the welfare of pets. Emma even stated that it is "much rarer than you'd think" for volunteers to have any personal connection to the charity shop they work for. This opposed the findings of Flores (2013) who found people were likely to volunteer in a shop if they had a personal affiliation with it. Both of the volunteers we interviewed cited the main reason for choosing PDSA over other charity shops was simply because of the easy application process.

Despite the disconnect between the volunteers and PDSA, we still imagined most of the volunteers took part for altruistic reasons. Unfortunately, Emma revealed there were a huge number of less selfless motives for wanting to do charity work, listing off reasons such as wanting to improve their language skills, work experience or wanting a routine.

This in itself we found quite surprising, as a previous study on charity shops conducted by Broadbridge found as many as $48 \%$ of volunteers "had a personal affiliation with the cause of the charity being investigated" (Broadbridge, 1994: 433). It is possible this difference is due to the location of the shop and the high proportion of younger, student volunteers who may not have a connection to people unable to afford veterinary care.

The closer we became with the staff, the clearer it was that the charity benefiting from their work was more of a pleasant coincidence; predominantly they had themselves in mind. Some of the most common reasons for volunteering was to gain work experience or obtain a Duke of Edinburgh award, which requires commitment to a charity in order to pass. In this sense, participants turn their charity work into a commodity, an impressive label to stick on CVs and University applications to improve their prospects.

Despite the negative connotations of our findings, we felt the charity shop was not a negative space. Our own enjoyable experiences within the charity shop made us reconsider our initial interpretations. While the "selfish" aspect of charity is evident, we began to understand charity less as a selfless gift and more in the form of a reciprocal exchange.

\section{Charity as mutually beneficial}

Back in the kitchen, 18-year-old Martin sits on a creaky wooden stool, sporting his usual grey fedora which tops up his fashion-forward outfit. Between his flashy fashion-sense and strong Manchester accent, you can always tell when Martin is in the room. He maintains his overwhelming presence on the shop floor too, making him the go-to person if we had any questions. If we arranged a new window display it had to be approved by Martin before it was seen by Emma. Despite his official status as a typical volunteer, Martin exudes the kind of poise on the shop floor which sparks questions as to why he gives up his time to PDSA beyond requirements for the Duke of Edinburgh Award.

Martin tells us he usually comes in three days per week, and more if he has the time, despite the requirement of the Award being just one. He then goes on to tell us that he enjoys spending time at the shop because of the social and uplifting atmosphere. For Martin, the shop is more than just the space in which he is able to fulfil his Duke of Edinburgh Award requirements, it is a home, a "family". While Martin's intentions to volunteer were not necessarily driven by altruism, there is certainly a sense of giving emerging in his attitudes toward working at the charity shop.

On the surface, the relationship between charity and volunteers promotes an exchange in which the volunteers provide labour to keep the shop running smoothly and the volunteers gain work experience, an improved CV or, in Martin's case, an award. However, the underlying exchange taking place between these two parties is not simply material. Rather, volunteers gain something intangible and indispensable through their work in the shop. For Martin, this comes in the form of a positive space he can look forward to being in. 
The PDSA shop provides a safe-haven for anyone and anything seeking refuge. Whether it is mismatched bone-china teacups or books with missing pages, the charity shop is a collection of what is without a place. Much like the quirky bric-a-brac piled onto the shop's shelves, Tracy (whose mental abilities limit her from working for pay elsewhere) finds her place here in the charity shop. Flores (2013) writes about the "therapy" voluntary work provides for people who have suffered personal trauma or loss. He describes volunteer work as "a way of regaining meaning, structure and belonging after experiences of social dislocation" (383) and this can definitely be translated into our space. It is a place where people who are not comfortable elsewhere can find employment and structure.

Volunteering is a mechanism through which "people are able to give meaning to their lives and (re-) gain a sense of ontological security" (Beck 1997 cited in Flores: 395). Despite the fact that Tracy might struggle in a standard employment position, here at the charity shop she is confident, making sure we, the novice volunteers, know what we are doing. Tracy is the smiling face in the pink t-shirt greeting you as you walk in the door; she is the recognizable pillar of this shop.

It is here we find ourselves every Thursday, surrounded by the mismatched jumble of items and assortment of volunteers who we have been politely interrogating for seven weeks. Perhaps one could say we too are in the shop for 'selfish' reasons, in conducting research for an ethnography, to boost our CVs, or to receive a good mark on our project. Like our counterparts in the shop we did not volunteer out of the goodness of our hearts; we did so with the intention of material gain and a mutual exchange. Despite our own selfish intentions, not only do we feel we have benefited the shop in terms of labour, but also that we, in turn, have gained something much more valuable than the completion of a project, ranging from a wider appreciation of the work that volunteers do, to new friendships.

\section{Conclusion}

Through our work in the PDSA Charity Shop, we have challenged common perceptions of what it means to be charitable. The charity shop itself is an example of the paradoxical nature of charity, as it represents an ethos of generosity in a business-oriented space which strives for profit. While the shop advertises its commitment to the charity through its animal-themed merchandise, there is an apparent disconnect between this space of monetary exchange and the cause benefitting from it. Furthermore, we have found that charity is not necessarily a one-sided exchange bounded in altruistic intentions, but instead constitute a mutual relationship where both parties benefit. Despite what can be perceived as 'selfish' intentions among some of the volunteers', their contributions to the shop benefit both the charity and themselves, whether in terms of employment, friendships, or happiness. Our findings have helped us to better comprehend the complex nature of charity as a reciprocal relationship.

\section{References}

Andreoni J. (1990) 'Impure Altruism and Donations to Public Goods: A Theory of Warm-Glow Giving' The Economic Journal. 100 (401): 464-477.

Crow, G., Wiles, R., Heath, S. and Charles, V. (2006) 'Research Ethics and Data Quality: The Implications of Informed Consent' International Journal of Social Research Methodology. 9 (2): 83-95.

Flores, R. (2013) 'From personal troubles to public compassion: charity shop volunteering as a practice of care' The Sociological Review. 62 (2): 383-399.

Horne, S. and Broadbridge, A. (1994) 'The charity shop volunteer in Scotland: greatest asset or biggest headache?' Voluntas. 5 (2): 205-218.

Parsons, E. and Broadbridge, A. (2006) 'Job motivation and satisfaction: Unpacking the key factors for charity shop managers' Journal of Retailing and Consumer Services. 13 (2): 121-131.

Malik, N (2008) 'Defining Charity and Charitable purposes in the United Kingdom' The International Journal of Not for Profit Law. 11 (1): 1.

Mauss, M. (1954). The Gift. 2002 ed. [ebook] Taylor \& Francis. Available at: https://libcom.org/files/ Mauss\%20-\%20The\%20Gift.pdf [Accessed 22 Mar. 2016]. 